\title{
REPRESENTACIONES DE LA MASCULINIDAD EN LA REVISTA CROMOS EN LA PRIMERA MITAD DEL SIGLO XX EN COLOMBIA ${ }^{1}$
}

\author{
Ani Yadira Niño Delgado \\ ay.nino41@uniandes.edu.co \\ Universidad de los Andes - Colombia
}

Recibido: 13-07-2015

Aceptado: 18-05-2016

\section{Resumen}

Este artículo hace una aproximación a la representación de las masculinidades en la primera mitad del siglo XX a través de la revista Cromos, examinando la construcción de estereotipos, sus continuidades y cambios. Se observará como en el tránsito del siglo XIX se ideó un nuevo modelo de hombría sustentado en la fuerza física y su relación con la configuración de un hombre guerrero para la consolidación de los discursos de nación. Se hace un acercamiento a través de las identidades relacionales y el esquema de oposiciones, observando el rol de lo femenino.

Palabras Clave: Masculinidades, estereotipos, identidades relacionales, publicidad, teoría de género.

\begin{abstract}
This paper aims to approach the representation of masculinity in the first half of the twentieth century through Cromos magazine, examining the construction of stereotypes, their continuities and changes. It is noted as in the late nineteenth century a new model of manhood supported by physical force is built and the importance of setting a warrior for the consolidation of the nation speeches. It's been made an approach through the relational identities and oppositions scheme, noting the role of the feminine.
\end{abstract}

Keywords: Masculinities, stereotypes, relational identities, advertising, gender theory.

\footnotetext{
${ }^{1}$ Este artículo se realizó gracias al apoyo de la Fundación Universitaria Los Libertadores (Bogotá, Colombia) en el marco del proyecto "Masculinidades en México D.F. y Bogotá y la influencia en la construcción del Estado-Nación y la familia".
} 


\section{Introducción}

Los estudios de las masculinidades en las últimas décadas han aumentado de la mano de los estudios de género, surgiendo de forma exponencial en los años 70 del siglo XX en los Estado Unidos. En muchos casos se piensa que el estudio de las masculinidades es la investigación del machismo, entendiéndolo como un fenómeno aislado, sin analizar los cambios históricos que complejizan la formación del individuo y la identidad de género en cada contexto socio-cultural $^{2}$. En el presente artículo se entiende que la masculinidad es una construcción social, y en tanto construcción es enseñada, aprendida, actuada y puesta en práctica. (Boscán, 2006). Por lo cual no podemos pensar de una única forma de vivir la masculinidad, sino de un concepto cambiante que responde también a las relaciones de poder de cada momento.

Es necesario comprender que a la hora de hablar de masculinidades e identidades de género, se está hablando tanto de lo masculino como de lo femenino, pues las identidades nunca se construyen sin lo otro. En este caso, la feminidad y la mujer se configuran como la alteridad de la masculinidad, para identificar lo que es ser hombre y lo que no; por ejemplo, en el caso de aquellas consideraciones negativas al señalar a un hombre que tiene ademanes "femeninos" como un no-hombre. En este sentido, si bien nuestro tema de interés son las masculinidades, debemos señalar que la figura de la mujer y la feminidad estarán presentes permanentemente pues estas identidades se construyen en oposición y relación.

Siguiendo con este argumento, Elena Faur señala como la definición de masculinidad se da en relación a la feminidad "La masculinidad existe en tanto exista la feminidad. Ya sea que se piense como complemento u oposición" (Faur, 2004: 49). Como veremos más adelante la identidad del hombre se construye en referencia a lo que no debe ser, con duros discurso contra los rasgos afeminados, como una blasfemia a la identidad masculina. Así, el análisis de la construcción de la identidad de lo masculino debe realizarse desde una perspectiva relacional y referencial.

Ahora bien, la masculinidad como concepto moderno está asociada a los atributos de honor y heroísmo, reforzada en el contexto de formación de los estados-nación, en la explosión de ideologías a finales del siglo XVIII y el periodo de revoluciones, tomando mayor fuerza en los momentos de confrontaciones bélicas. En la segunda mitad del siglo XX el análisis de la masculinidad empieza a recibir gran interés, especialmente entrado el siglo XXI con el despliegue de nuevas masculinidades que hacen contrapeso a eso modelo ideal de lo masculino y plantean la discusión sobre lo que se había considerado durante años como natural del ser hombre. En palabras de R. W. Connell se generó una "fractura de la masculinidad de la

\footnotetext{
${ }^{2}$ Para el caso de la situación actual en Colombia vale la pena examinar el texto Masculinidades y desarrollo social. Las relaciones de género desde las perspectivas de los hombres, que reflexiona los temas de identidad sexual, violencia y equidad de género en relación con las estructuras sociales y familiares.
} 
aristocracia, su desplazamiento gradual por parte de las formas hegemónicas y el surgimiento de toda una serie de masculinidades subordinadas y marginadas" (Connell, 2003: 257).

Si bien, muchos de los estudios actuales están enfocados a analizar las nuevas formas de masculinidades y cuestionar la forma en qué se ha naturalizado, también es importante examinar las raíces de esos procesos y las continuidades o discontinuidades que se presentan en los discursos de género. Esto advirtiendo que junto con la existencia y aumento de nuevas formas de masculinidades, también persisten arraigados estereotipos de lo que se considera debe ser un hombre. La masculinidad se constituye como símbolo, por lo cual las imágenes y la reproducción visual de lo que es ser un hombre se hace tan importante. Teniendo en cuenta lo anterior, este artículo se centra en la representación gráfica de la masculinidad en la primera mitad del siglo XX, para identificar los estereotipos, continuidades y cambios que se dan en estos años.

\section{La prensa y representación de género}

La historia de la prensa y los diarios en Colombia empieza hacia finales del siglo XVIII, con el Aviso del Terremoto de Antonio Espinosa de los Monteros (1785), la Gazeta de Santafé de Bogotá y el representativo Papel Periódico de Manuel del Socorro Rodríguez, en 1791. A lo largo del siglo XIX los periódicos, diarios, revistas y papeles impresos se difundieron con gran rapidez como medio de construcción y expresión de la opinión pública, como lugares de información, de quejas y reclamos. Hacia la segunda mitad del siglo XIX los impresos se fueron consolidando como espacios de socialización y se especializaron con la aparición de revistas literarias o de carácter humorístico.

En 1879 se dio a conocer la revista La Mujer, fundada por Soledad Acosta de Samper, que muestra la situación social de la mujer en medio de los discursos en favor del progreso y la modernidad. Un ejemplo del impacto de esta revista se puede observar en la publicación de "Los Tratados para la Mujer" de Madame de Lambert ${ }^{3}$, que analizan la condición femenina y cuestiona las costumbres que oprimían a la mujer. También se encuentran análisis históricos sobre la mujer en los diferentes momentos de la civilización.

La fundación del Papel Periódico Ilustrado en 1881, por parte de Alberto Urdaneta, se configuró en un hito para la prensa de la primera mitad del siglo XX, seguido por revistas como Cromos y El Gráfico que dieron gran preeminencia a la imagen, las cuales empezaron a distinguirse de los diarios netamente informativos e incluyeron secciones que abordaban la vida moderna, espacios literarios, de opinión y de intercambio con la audiencia.

\footnotetext{
${ }^{3}$ Para ampliar el análisis sobre la influencia de los Tratados de Madame de Lambert vale la pena observar el estudio de María José Bono Guardiola (2006), que recopila los más importantes textos de Anne-Thérèse Marguenat de Courcelles, también conocida como la Marquesa de Lambert (1647-1733).
} 
Teniendo en cuenta la importancia que adquirieron los medios de comunicación impresos en el siglo XX para construir y difundir los estereotipos de género, a continuación se hará un barrido de las revistas sociales del momento, señalando los cambios que se manifiestan a través de las décadas de la primera mitad del siglo XX en la representación del género, para luego enfocarnos en algunos aspectos relevantes que dan cuenta de los cambios y continuidades que se observan en la representación de lo masculino, teniendo como fuente principal los avisos publicitarios y propagandas de la revista Cromos por su importancia gráfica y su duración, con casi 100 años de vigencia.

\section{- 1910}

Revistas como Cromos (1916) y El Gráfico (1910) prosperaron hacia la década de 1910 en Conmemoración del Centenario de la Independencia, estas revistas surgen con un espíritu renovador y la seguridad que el país inicia un camino hacia la modernidad, tras superar la Guerra de los Mil Días. Como señala Santiago Castro-Gómez, la Exposición Agrícola e industrial que se desarrolló en el marco del Centenario "creaba simbólicamente tal ilusión de progreso [...] la exhibición de 1910 funcionó como un aparato construido para interpelar a los individuos en tanto sujetos moderno" (Castro-Gómez, 2008, p. 230). El uso de imágenes y gráficas será una forma de atraer al público, pero más que nada, promover la noción de progreso a la que debía aspirar la sociedad.

\section{- 1920}

Hacia la década de los años 20 se empieza a conceptualizar sobre feminismos y los avances de la mujer, se menciona el tema con entusiasmo pero también con cierto resquemor y escepticismo. El asunto de la mujer se vuelve novedoso y empieza a ocupar las páginas de la prensa por ser noticia en las principales ciudades de Europa y Estados Unidos. Sin embargo, es de observar que prevalecieron las opiniones conservadoras en relación al rol de la mujer en el hogar, asociadas a la salvaguardia de las tradiciones, la familia y la religión. El argumento siempre argüido será la importancia de la familia como pilar de la sociedad y, en especial, de la mujer como responsable de la educación de los hijos.

\section{- 1930}

Hacia la década de los treinta se puede apreciar un cambio radical frente a la representación del cuerpo y del género. La mujer aparece como un referente de consumo, con un sinnúmero de productos de belleza y salud ofertados para su puesta en escena social. Por su parte, la imagen del hombre pierde un poco de formalidad y también es asociada a productos de belleza. De esta forma, el cuerpo masculino también se convierte en objeto de idealización. La 
representación masculina sufre una especial transformación, asociado al soldado y al hombre que se sacrifica en la guerra. Esto como resultado, por un lado, del influjo de la Guerra con el Perú que se desarrolló entre 1932-1934, y por otro también responde a los postulados de la construcción de la masculinidad que se dan desde el siglo XVIII con la Revolución francesa y las guerras nacionalistas. Así pues, la guerra con el Perú servirá para consolidar esta imagen de la masculinidad como un hombre que se sacrifica por un ideal, la nación y que engrandece sus virtudes.

\section{- 1940}

La figura del cuerpo toma relevancia. La idea de un hombre delgado es cuestionada y es puesta en oposición con un cuerpo robusto y saludable. Ahora el cuerpo no solamente es objeto de interés, sino que se convierte en el símbolo de lo que debe ser un cuerpo sano, vigoroso y fuerte, un ideal que buscan borrar todo rastro de mestizaje. Un proceso que es liderado en países europeos, especialmente en Alemania donde se empieza a crear la imagen de un hombre perfecto y un estereotipo de la masculinidad. Dicho de otra forma, se afianza un ideal de belleza masculina influenciado por los estereotipos de la Segunda Guerra Mundial y el discurso fascista frente a la limpieza de razas.

\section{Construcción del macho}

En 1925 en el periódico El Nuevo Tiempo el presidente Pedro Nel Ospina manifestó que Colombia necesitaba una "generación de machos" que guiara al país. Como reacción a esta afirmación en la revista Cromos rebatió Pedro Pérez (Cromos, 15/08/1925) cuestionando si realmente lo que le hacía falta a Colombia eran hombres atléticos $\mathrm{y}$ robustos, o inteligentes $\mathrm{y}$ preparados. El artículo de Pérez refuta la afirmación de Ospina, haciendo referencia a la batalla entre Goliat y David, en la cual la fuerza cae debilitada contra la inteligencia. Pérez recuerda que Grecia no fue dirigida por los atletas sino por filósofos e intelectuales, igualmente argumenta que los emperadores romanos Julio César y Augusto, pese a sus debilidades físicas, crearon el imperio más grande de la antigüedad. Para Pérez los grandes avances y cambios en la humanidad son

Imagen 1. ¡Hasta que caiga uno!

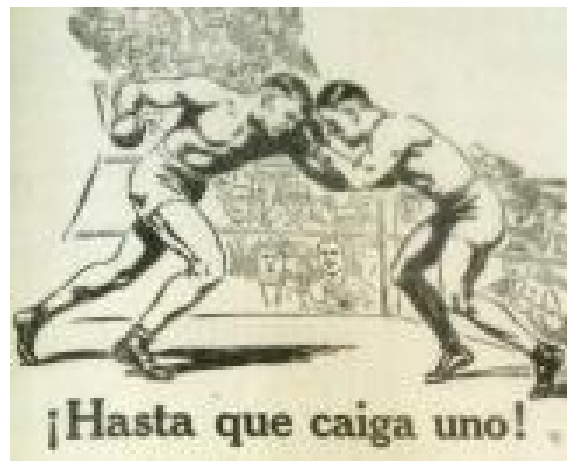

Fuente: Cromos, 2/08/1924. 
producto de la inteligencia y no del macho, por lo cual hace un llamado a reevaluar la opinión del presidente Ospina.

En esta disputa podemos apreciar el debate que estará a lo largo de la primera mitad del siglo XX, con el triunfo de la representación de un hombre "macho" que busca unir la fuerza y los valores heroicos.

Como señala Gloria Espigado en su artículo "Cómo hacerse un hombre. La pedagogía decimonónica al servicio de la construcción de la identidad sexual” (en Ramos: 1997), la familia, la escuela y la sociedad cumplían un arduo trabajo para enseñar al niño a hacerse hombre y practicar la hombría. Espigado hace un acercamiento a la construcción de la identidad masculina a partir de los diccionarios de pedagogía que buscaban formar una identidad sexual. Si bien se consideraba que el hombre al nacer tenía un estado de superioridad inherente, era necesario enseñar y poner en practicar la hombría.

Hacia finales del siglo XIX y comienzos del siglo XX la escuela será un baluarte para la construcción de ese macho que debía sustentar la nación. El niño y el joven eran objeto de diferentes estrategias para asegurar su correcta formación, sin afeminamientos y con la robustez del macho.

En esta medida, la cultura física apareció para moldear a los nuevos ciudadanos, esta disciplina se instituyó a principios del siglo XX de la mano de la higiene y los manuales de urbanidad. Estos procesos buscaban el control del individuo y su disciplinamiento en un espacio moderno, que establecía cómo debía comportarse. Precisamente la educación del cuerpo se convirtió en un tema central dentro de los discurso de modernidad y progreso, la construcción de ciudadanos estaba asociada tanto a su disciplinamiento moral e intelectual, como a modelar su capacidad física. Un cuerpo sano y fuerte debía ser reflejo de un individuo capaz de apoyar las tareas de modernización del país.

El avance del estereotipo del "macho" se puede apreciar en la transformación de la representación masculina en la publicidad de las revistas. Entre los años 1910 a 1920 se evidencia la reproducción de un hombre "romántico", bien vestido, no muy corpulento, con expresión taciturna o muy formal. Al pasar los años vemos la introducción de un hombre fuerte con atributos guerreros, con torsos desnudos que delinean un cuerpo ejercitado.

En este sentido, la publicidad de las revistas tuvo un papel determinante en la nueva representación del cuerpo. Como se ha mencionado anteriormente, la revista Cromos significó un gran aporte en el uso de la imagen y de los discurso modernos, como señala Zandra Pedraza fue "un magazín que apadrinó los más variados discursos sobre el cuerpo moderno" (1999: 19)

\subsection{Deporte: espacio de sociabilidad masculino}

Ahora bien, la educación del cuerpo nos habla no solo del disciplinamiento al individuo que empieza a imponerse junto con la eugenesia, sino que también pone en circulación nuevos 
círculos de sociabilidad masculinos. Los equipos y justas deportivas emergen como espacios de integración e identidad.

El desarrollo del ejercicio físico aparece con gran ímpetu, rasgo que se puede apreciar en Cromos al inaugurar una sección exclusiva para este tema, con gráficas y artículos especiales, que destacan la labor del deporte tanto en la conformación de un cuerpo sano como en la construcción de la sociedad.

La introducción de actividades físicas dentro del programa pedagógico se dio con la Ley General de Educación de 1903, de esta forma ciertos deportes entraron en un espacio privilegiado por ser considerados más aptos para constituir un cuerpo nacional fuerte y ágil. Siguiendo a Pedraza (2011: 453) "Los objetivos de la educación física resultan del esfuerzo de la modernidad por

\section{Imagen 2. Deportes}

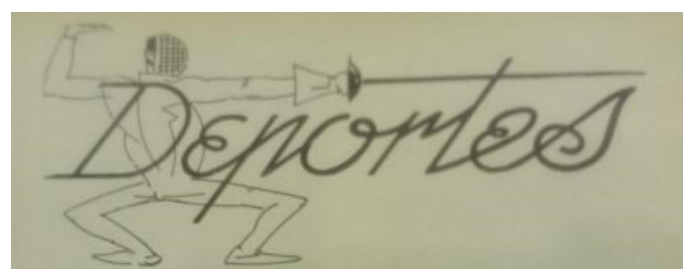

Fuente: Cromos, 05/03/1938 perfeccionar la condición humana, en especial, por la importancia atribuida al cuerpo en este propósito."

Las competencias deportivas fueron registradas en la prensa como parte de los eventos sociales, resaltando el valor físico de los participantes y sus atributos "masculinos", con preeminencia de aquellos deportes que hacían ostento de la fuerza física como el boxeo. En la revista se ve el registro de los encuentros boxísticos que se hicieron populares en la década de los veinte, al mismo tiempo que se constituía la Federación de Boxeo de Colombia en 1922 y un amplio número de aficionados se daban cita en el teatro Olimpia, entre otros de los teatros de la ciudad, para ver tanto a pegadores nacionales como internacionales. En una de las entrevistas realizadas al campeón nacional, Rafael Tanco, antes del combate con un boxeador estadounidense, se resaltan sus cualidades varoniles, su cuerpo helénico, su régimen de entrenamiento; así como su elegancia y distinción, exponiendo estos atributos como modelos a seguir. Igualmente en 1938 cuando se desarrollaron en Bogotá los Primeros Juegos Bolivarianos, Cromos hizo un amplio despliegue con reportajes de las diferentes disciplinas incentivando a los niños a la práctica deportiva.

Así pues, el ejercicio físico y el disciplinamiento aparecen como formas de depurar o mejorar el cuerpo social, modificar las costumbres bárbaras y moldear un cuerpo para el trabajo y el ejercicio sano de la ciudadanía, fortaleciendo el poder biopolítico que regía la vida y cuerpos de sus ciudadanos. María del Carmen Suescún señala que con el régimen liberal iniciado en los años treinta se dio un giro hacia la modernización y el cuerpo apareció como centro de debate partidista, ya que “... el cuerpo fue cargado con un poder capaz de reconciliar estructuras seculares y religiosas durante tiempos peligrosos..." (Suescún, 2007: 254). En las palabras de Suescún debe advertirse el valor simbólico que adquiere el cuerpo, en especial el 
cuerpo masculino como representación de un pueblo nacional, que construye su identidad en la fuerza de sus hombres.

La representación de lo masculino se asume desde la representación de su corporeidad, su virilidad y su competitividad, como símbolo de la condición corporal de la nación. Como señala George Mosse durante la Revolución francesa "la propia estructura del cuerpo masculino se convirtió en símbolo de una nación y una sociedad sanas (Mosse, 2000: 35).

La construcción de la masculinidad estaba moldeando un estereotipo de belleza, serenidad, moralidad, fuerza y autocontrol que reflejaba la imagen que la sociedad quería tener de sí misma. Estos atributos hacen que la debilidad sea considerada un mal que no es propio del macho.

En este sentido, vale mencionar los medicamentos que aparecen para ayudar a fortalecer el cuerpo y la virilidad, advirtiendo claro, que la debilidad del hombre se produce por el exceso de trabajo físico y mental, pero no es algo congénito, contrario a la debilidad

Imagen 3. ¡Débil, Agotado!

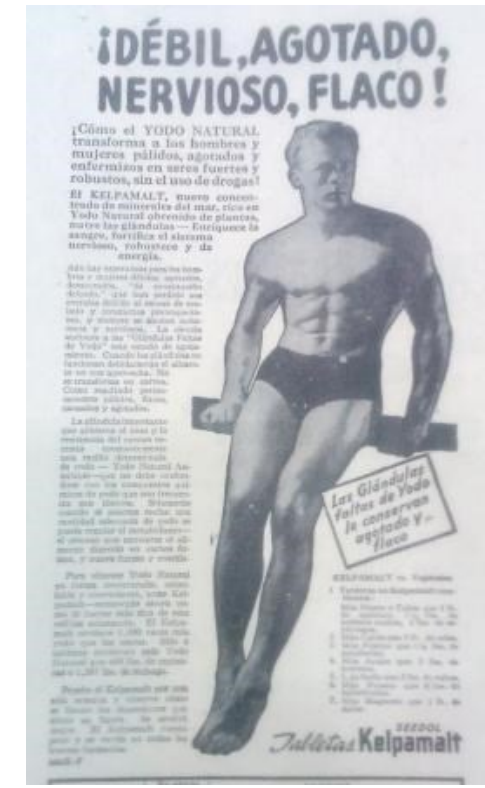

Fuente: Cromos, 03/10/1936 natural de las mujeres, como más adelante veremos.

Estos revitalizadores se sustentan tanto en el discurso competitivo del deporte como en los ideales de progreso e individualismo difundidos en la modernidad. Así pues, el cuerpo se convertirá en el eje de la virilidad, un cuerpo sano y fuerte representa el ideal, el macho que para el presidente Pedro Nel Ospina debía guiar la nación.

\section{Construcción del guerrero}

En este apartado nos enfocaremos en cómo la imagen del hombre se constituye no solo en el modelo del cuerpo de la nación, sino en su defensor o guerrero. Desde el proceso de Independencia el hombre de armas se constituyó en el defensor de la patria y los ideales republicanos. Los personajes que adelantaron las campañas libertadoras aparecen como los primeros grandes republicanos, revestidos de heroísmo, valor y sacrificio por la patria. Precisamente la condición de ciudadanía es adquirida por el ejercicio viril de lucha. Lo que distingue a los verdaderos ciudadanos y compatriotas es el valor de empuñar un arma y dar la vida por la patria. 
Mosse expone como los nacionalismos que surgen a finales del siglo XIX toman parte de los atributos del caballero de la edad media e igualmente adoptan el ideal de masculinidad para fomentar la defensa e identidad nacional, con una triada que asocia masculinidad, patriotismo y nacionalismo. Así "la noción de que el hombre de verdad debe servir a un ideal más alto, llegó al final a ser parte integrante de lo que podía ser llamado la militarización de la masculinidad" (Mosse, 2001: 55). Las guerras que atravesaron la primera mitad del siglo XX se sustentaron en ese estereotipo de un hombre guerrero que lucha por un ideal.

Retornando al contexto colombiano, hacia el mes de septiembre de 1932 Colombia enfrentó el conflicto con Perú, generado por la invasión de Leticia por parte de un grupo de ciudadanos peruanos, lo cual provocó múltiples discursos patrióticos en tono guerrerista. Durante los primeros meses la prensa reprochó sutilmente la actitud pacifista que el gobierno colombiano había asumido. Se

\section{Imagen 4. Feliz año}

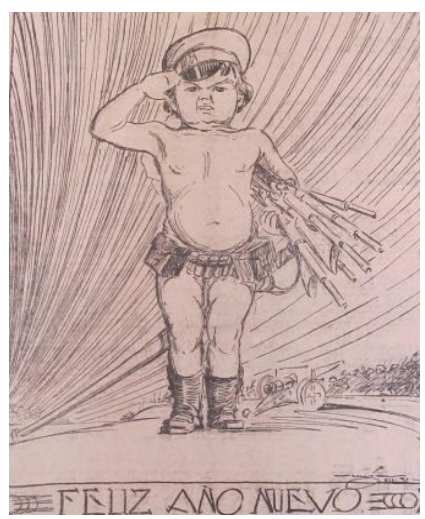

Fuente: El País, 31/12/1932. esgrimió que no asumir la guerra contra Perú no sólo colocaba en peligro la existencia de la nación colombiana, sino el honor y el carácter varonil de la misma. La guerra se planteó en términos de hombría y no solamente por la defensa del territorio fronterizo.

En este contexto puede entenderse la imagen de celebración de año nuevo de 1932 que aparece en la primera página del periódico El País y que representa a un niño con botas y gorro militar, cargado de armamento. Retomando a Pedraza, es importante tener en cuenta que dentro del proceso civilizatorio que se venía desarrollando en Colombia, la cultura física también

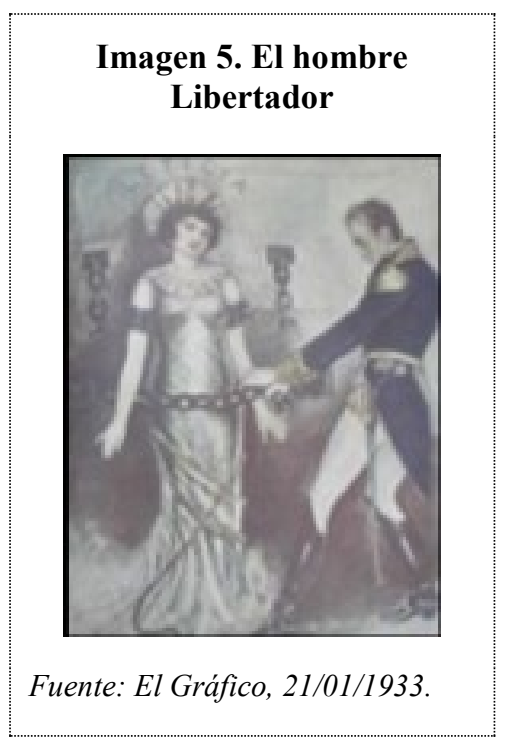
estaba dirigida para "garantizar el aprestamiento de los niños para el servicio militar" (1999: 220).

Es así como la guerra contra Perú sirvió como justificación para ahondar en los procesos de integración y ciudadanía, haciendo más hincapié en los deberes y normas que debía cumplir cada ciudadano, que en sus derechos. La muerte por la defensa de la nación fue un argumento difundido extensamente por la prensa que, vinculado con el honor masculino, fortalecía el antagonismo con Perú e instigaba a conformar las filas militares. El reclutamiento se exhibía como el mayor sacrificio que cualquier ciudadano podía ofrendar. En esta representación guerrerista del mundo surgió la imagen del soldado como el salvador de la nación: "Hoy me sueño con la gorra, el uniforme y el equipo de dos 
arrobas y media del soldado colombian ${ }^{\circ}$. Ahora que la boca de los oradores se calla para que hable la boca de los bélicos cañones, encuentro en el soldado al heraldo de la epopeya" ("Soy soldado". La frontera, 09/10/1932). La función de guerrero estaba reservada para el hombre en una sociedad que "establece roles de defensa, de cuantos peligros acechen a los seres débiles mujeres y niños-, y se los encomienda a los hombres" (Ramos, 1997: 273).

Quién mejor podía representar la imagen del soldado que acudía a la defensa de la patria era Simón Bolívar. Su imagen se convirtió en una figura recurrente tanto en el discurso, como en las ilustraciones. Bolívar aparecía dirigiendo a los escuadrones a la frontera o liberando a Leticia. En la portada de la revista El Gráfico del 21 de enero de 1933, Leticia es representada como una mujer libertada por Simón Bolívar. Desde esta perspectiva se podría analizar que la guerra se presenta como una confrontación para demostrar la hombría de Colombia y Leticia como la mujer-botín de guerra que se lleva el hombre que demuestre su valentía. Es una forma de acercar el conflicto binacional al imaginario cotidian ${ }^{\circ}$. Al mostrar la mujer en peligro que clama por ayuda, se acentúa el honor varonil que estaba detrás de los argumentos de batalla. Siempre en esta formación de identidades relacionales y referenciales, es donde la presencia de la mujer ayuda a construir la identidad masculina valiente, fuerte y protectora.

Cromos paralelamente a la información brindada sobre los últimos acontecimientos del conflicto, dedicó un espacio para recopilar los relatos de viajes al Amazonas y las misiones con un amplio repertorio fotográfico de las poblaciones indígenas, las costumbres y las características geográficas. En una comunicación del médico Eugenio Salas a la revista, se hace una descripción de las poblaciones indígenas que se encuentran en el Amazonas, subrayando los atributos corporales de fuerza y resistencia de algunas tribus indígenas (cofanescoreguajes) pero lamentando que "no prestan al país el concurso que debieran. Viven solitarios, lejos del mundo civilizado, no se les ha inculcado el orgullo de ser colombianos, el íntimo sentimiento del patriotismo" (Cromos, 24/09/1933). Salas mantiene la visión del indígena bárbaro y sumiso, pero rescata sus atributos corporales que pueden servir al país.

\section{Imagen 6. Pueblo Sano}

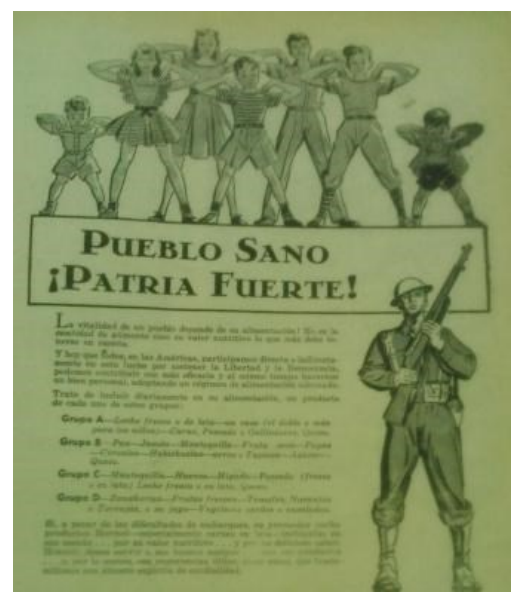

Fuente: Cromos, 20/03/1942.

"En 30 días estos indios pusilánimes que vestían faldas, se han transformado en hombres y serán soldados... Ya tienen el orgullo de ser soldados colombianos. Mañana sabrán amar la patria y el país tendrá en ellos no un grupo de indios degenerados e inútiles, sino habitantes efectivos" (Cromos, 24/09/1933). 
No deja de llamar la atención que en medio de este contexto bélico, las comunidades indígenas hayan sido llamadas a combatir y el servicio militar se hiciera obligatorio, pero más aún que la forma de convencer a los indígenas, se diera a través de la utilización de argumentos contra los rasgos afeminados, como el uso de "faldas" prenda asociada a las mujeres. Consolidando nuevamente la identidad masculina en oposición a lo femenin ${ }^{\circ}$.

Igualmente, puede apreciarse como se descalificaban y menospreciaban las costumbres de los indígenas, pero se reivindicaba su salvación al constituirse como soldados en beneficio de la nación; se les nombraba como ciudadanos colombianos, subrayando los deberes que tenían con la defensa nacional, pero omitiendo los derechos que podían ejercer.

Estos discursos guerreristas que tuvieron gran difusión durante el conflicto colombo-peruano entre los años 19321934, encontraron continuidad con las noticias venidas de Europa en medio de la Segunda Guerra Mundial y la expansión de los regímenes fascistas, la imagen del soldado y de la lucha por un ideal se consolidó como un atributo

\section{Imagen 7. El Duce: Hombre fuerte}

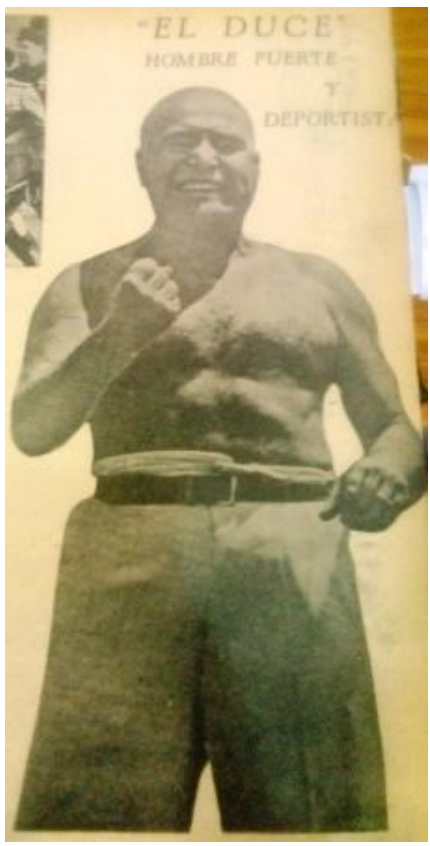

Fuente: Cromos, 07/10/1939 varonil.

En este sentido, George Mosse enfoca la última parte de su texto en la influencia que tuvo el nacionalismo alemán e italiano en la consolidación del estereotipo masculino sustentando en el ideal de belleza corporal, virilidad y capacidad de lucha o competitividad: "Nunca antes ni después de la aparición del fascismo fue elevada las masculinidad a tales cumbres: las esperanzas puestas en ella, la importancia de la masculinidad como símbolo nacional" (Mosse, 2001: 181).

En el caso puntual de Alemania, tanto el deporte como los avances médicos estuvieron fuertemente dirigidos a consolidar esos estereotipos de masculinidad.

Durante los años de la Segunda Guerra Cromos presenta permanentes reportajes sobre los ejércitos alemanes e italianos, con un tono bastante ambiguo respecto a los líderes fascistas que algunos momentos son representados como arquetipos de la virilidad y heroísmo.

Un mes después de la invasión de Polonia por parte de Alemania y del inicio de la guerra en Europa, Cromos hace un despliegue respecto de la figura del otro líder fascista del momento, Mussolini, señalando "Nadie niega ya las dotes geniales y la extraordinaria capacidad política de Benito Mussolini" (Cromos, 07/10/1939). Estas referencias rescatan los atributos varoniles y la disciplina corporal del duce, así como su capacidad de dominar y proteger a las masas que lo siguen. 


\section{Mujer: debilidad y feminismo en boga}

El tema femenino atravesará la opinión pública de la primera mitad del siglo XX, con la influencia de movimientos feministas que empiezan a surgir desde Europa y Estados Unidos. Si bien es valioso el reportaje que se hace sobre el tema, se observan algunas posturas señalando que las feministas de Estados Unidos pierden los atributos femeninos. En 1922 Juan Valdez presenta una serie de reportajes sobre los avances del feminismo en Europa, señalando que las mujeres en Colombia debían seguir el ejemplo y luchar por sus derechos, igualmente se señala la participación de la joven colombiana Rubi Gutiérrez como delegada de Paraguay a la Conferencia Femenina en Baltimore de mujeres, resaltando sus valiosas capacidades que la hicieron ser representante de dos países latinoamericanos. En la entrevista la joven colombiana cita las palabras en la conferencia de Carrie Chapman Catt, importante líder feminista de la época, señalando que el propósito era "tratar de llevar a nuestros países las bases para la reformar progresivamente la educación moderna en la mujer hasta conseguir el completo goce de todos sus derechos" (Cromos, 10/06/1922).

Esta preocupación por las corrientes feministas estarán presentes durante toda la década de los veinte, sobre el avance en la igualdad política de los sexos y la lucha feminista, con términos innovadores que se sumaban a la causa de las mujeres y exigían un trato igualitario como ciudadanas libres; señalando la opresión ejercida por el hombre "derechos que han sido usurpados por parte del hombre a la mujer ("Feminismo y feministas" Cromos, 4/08/1923).

Otro de los recurrentes artículos que salieron en la década del 20 sobre el feminismo, habla del feminismo en Francia y la declaración de los derechos de la mujer, así como de combate por el voto femenin ${ }^{\circ}$. En este artículo se presenta una distinción entre las mujeres feministas de Europa y las mujeres feministas de Norteamérica, señalando que las primeras no pierden la esencia y delicadeza femenina, mientras las de Estados Unidos buscan igualarse al hombre en todo $\mathrm{y}$ se hacen marimachos, perdiendo sus cualidades (Cromos, 27/06/1925).

Sin embargo, llama la atención que al avanzar los años este tema se convierte en objeto de burla y mofa, después de observar artículos promoviendo los derechos de igualdad de las mujeres, se extienda una visión negativa respecto a las ideas feministas considerándolas contrarias a la moral, la religión y el deber ser de la mujer en el hogar. La más fuerte oposición contra las ideas

\section{Imagen 8. La mujer moderna considera de mal gusto el estar enferma}

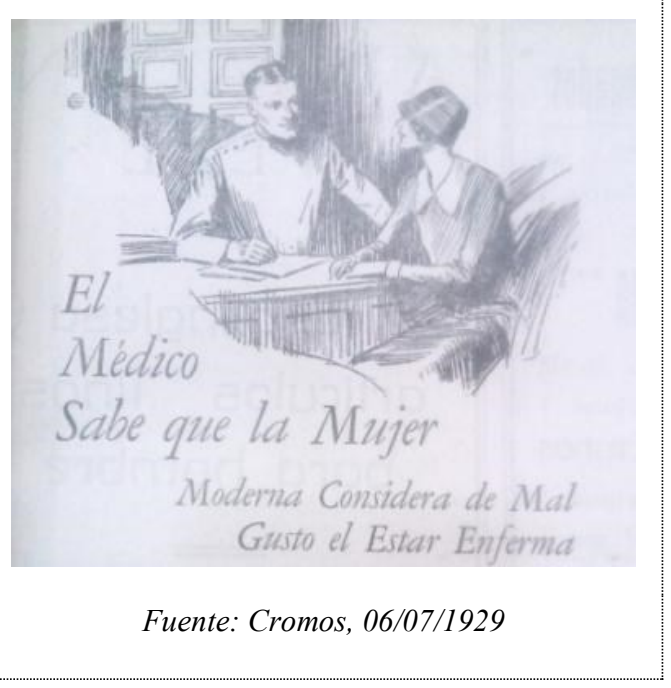


feministas y la preparación profesional de la mujer se fundamentaban en el abandono al hogar y la familia, recordando que el fin de la mujer era ser madre y dirigir el hogar.

La publicidad dirigida a la mujer estaba enfocada en su labor doméstica, como madre o esposa; los productos de belleza apelaban a argumentos para conquistar un esposo y hacerlo feliz. Para observar cómo la mujer sirve como referente identitario para la masculinidad podemos analizar tres facetas en las que se presenta lo femenino: 1) Mujer como un ser débil, que enfatiza la fuerza del hombre; 2) Mujer-esposa, que la reduce en función al matrimonio; 3 ) Mujer-madre.

\subsection{Mujer: débil}

La mujer en su estado natural se ve como un ser débil, frívolo, nervioso e inconstante. Este aspecto es aprovechado por los productos que están dirigidos a ella para mejorar su estado de ánimo y su natural debilidad. Hacia los años treinta y entrada la década de los cuarenta, son diversas las campañas publicitarias de medicamentos, vitaminas y otros artículos que aparecen como solución para la supuesta debilidad de las mujeres. Es de anotar que si bien para los hombres también hay productos para fortalecer su cuerpo, se señala que por su trabajo mental o físico es elemental que estén agotados, sin embargo en las mujeres, es algo congénito, que reside en su débil naturaleza femenina. Como parte de la argumentación que promovía un tónico vegetal para la salud de la mujer se utiliza el concepto de modernidad, señalando que la "mujer moderna considera de mal gusto el estar enferma", dejando claro que sus indisposiciones físicas son "razón de funciones meramente femeninas". Pero esta propaganda no se limita a depreciar el cuerpo de la mujer por su naturaleza débil, sino que promete que el producto elimina el problema de raíz "Tenga ud. A mano una botella y se olvidará de que es mujer" (Cromos, 06/07/1929). Así pues, la enfermedad de la mujer es precisamente su "ser mujer", lo femenino debe ser eliminado u ocultado para lograr encajar en esta nueva sociedad que requiere individuos fuertes y productivos.

Pero además, estos cuidados no se dan por el propio interés de la salud femenina, sino por su necesidad de buscar y mantener un marido, así la propaganda dirá "una Mujer anémica no puede ser cariñosa”. Igualmente, se encuentran numerosas propagandas dirigidas a las mujeres, en las cuales se señala que de su belleza y presentación personal dependen la conquista de un hombre y su realización como mujeres. La mujer aparece como símbolo de deseo del hombre, que debe estar al servicio de éste; como señala Mosse (2001: 35) de acuerdo al código napoleónico que se extendió por Europa la mujer debía obediencia al hombre. Este discurso era reproducido insistentemente en la publicidad, dejando claro el estado de superioridad tanto física como social del hombre, respecto de la mujer. 


\subsection{Mujer Esposa}

Así los cuidados y la belleza de la mujer están enfocados en ser una buena esposa. El matrimonio es para la mujer el fin, el principal objetivo de su vida, mientras que para el hombre la conquista de una mujer es el medio para construir su identidad masculina. "Así que el hombre vive la conquista de la mujer no como un fin, al contrario que esta, sino como medio para conseguir su identidad masculina" (En: Ramos, 1997: 91).

El matrimonio es visto no como una unión de iguales, sino algo que enaltece a la mujer y la separa de su estado inferior. Llama la atención que en cada edición de la revista las páginas sociales registren mínimo un matrimonio, siendo los más importantes cubiertos con amplios despliegues fotográficos.

La publicidad de las revistas muestra la debilidad de la mujer como una amenaza para la estabilidad de la familia. Se insiste que una mujer nerviosa no puede ser "aguantada" por su esposo y arriesga su matrimonio: "una madre enfermiza y doliente priva a su esposos y a sus hijos de la vida placentera y dichosa del hogar". Este discurso insiste en la debilidad congénita de la mujer y su subordinación hacia el hombre. Además, que la debilidad del cuerpo significaba una mala capacidad para tener y criar los hijos, considerada la función primordial de la

\section{Imagen 9. A todo hombre le deleita que su esposa sea fuerte, robusta y cariñosa}

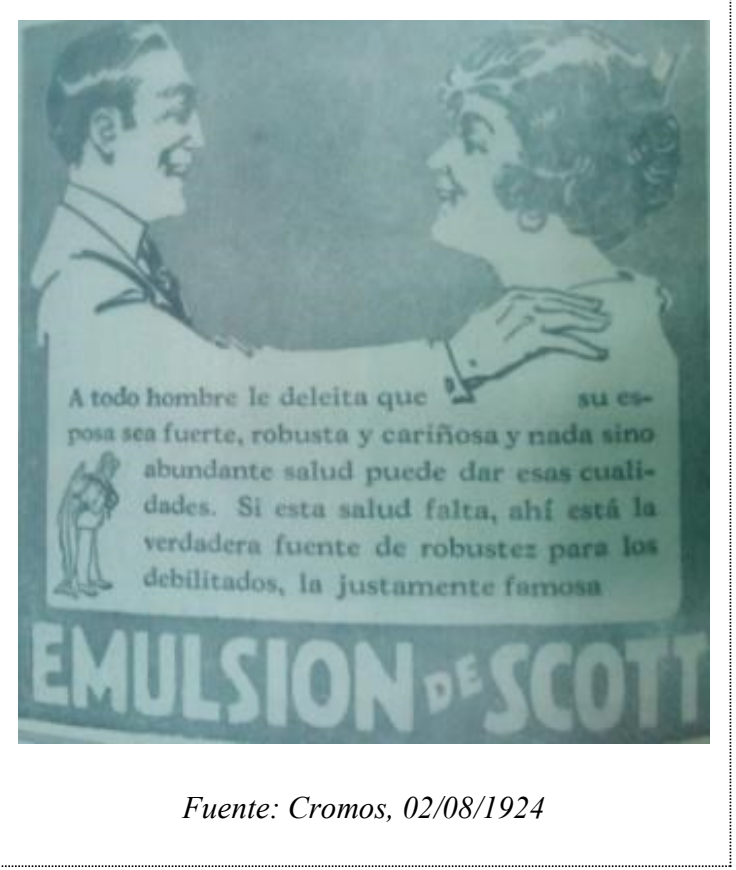
mujer.

\subsection{Mujer: Madre}

La tercera faceta que representa a la mujer, quizás la que encierra todas las anteriores, es su vida como madre, que incluye todo el tema del hogar, se insiste en la necesidad de fortalecer el cuerpo femenino para que pueda dar buenos hijos y en su capacidad de educar y de mantener correctamente la casa.

A partir de los años treinta aparece una sección especial dedicada a cómo manejar el hogar y el cuidado de la casa, reproduciendo la figura del "el ángel del hogar" sumiso y dependiente de las tareas domésticas. 
La mujer-madre debía apoyar el proceso de la civilización y consolidar la unidad familiar para constituir la obediencia de los hijos a los padres y de los ciudadanos al Estado ${ }^{4}$. Frente a la imagen de la mujer-madre en el siglo XIX, Zandra Pedraza señala que: "Era en la maternidad donde se desplegaba la verdadera condición femenina.

Los higienistas fraguaron la imagen de la mujer-madre, figura suprema del orden social imaginado por ellos [...] haría del hijo un ciudadano útil $\mathrm{y}$ de la puericultura una obra patriótica. Portadora de salud moral y física, ella era la figura esencial, la que posibilitaba el trabajo masculino- y por ende el bienestar social-, la cristalización del amor que perpetuaba la unidad familiar" (1999: 187).

Como hemos señalado hacia los años veinte los discursos fueron más diversos y presentaron alternativas para que la mujer pudiera desarrollarse

\section{Imagen 10. Cuide la felicidad de su hogar}

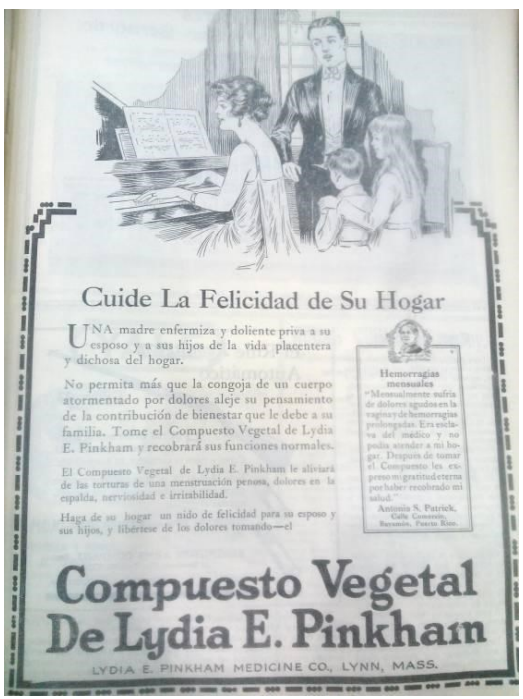

Fuente: Cromos, 08/03/1924 en otras facetas de su vida. Por ejemplo, en un artículo sobre la mujer como pilar de la familia, se resalta la importancia de la educación femenina para ser buenas madres y responder ante la administración de hogar. A continuación se presenta un fragmento del discurso pronunciado por la colombiana María Suárez de Coronado en Washington durante un banquete ofrecido por american women's conference, dice: "el ideal de la mujer, digna de la enorme responsabilidad de formar y dirigir una familia sólo se alcanzará cuando tengan en cuenta que debe dársele una educación integral" (Cromos, 06/06/1925). Igualmente señala que la "prosperidad social descansa en la prosperidad de las familias". Su argumento se dirige a la importancia de fomentar una educación femenina moderna y práctica, que ayude a las mujeres a enfrentar los problemas diarios de la administración del hogar y a su vez ayuden a educar a los hijos en la moral y en las normas que rigen el mundo modern ${ }^{\circ}$. Finalmente, es responsabilidad de la mujer forjar el futuro de la sociedad, "Es de ella que puede esperarse la renovación social, renovación suave, toda cordura, cariño y paz" (Cromos, 06/06/1925).

Sin embargo, por más visiones o posiciones alternativas y modernas, la mujer seguía siendo la responsable de la crianza de los hijos, la figura que sostenía y de la cual dependía la

\footnotetext{
${ }^{4}$ Vale la pena señalar que esta representación de la madre también hacía alusión al culto de la virgen María, madre de Dios. Desde la religión, la madre también cumplía un importante papel en educar a los hijos en la religión, en guiar moral y religiosamente a la familia. Entonces las madres además de educar al niño en el amor a dios, deben educarlo en el amor a la patria y en el sacrificio que deben cumplir.
} 
estabilidad de la familia. En este sentido las imágenes y reproducciones asociadas con familia y los hijos hacen directamente responsable a la mujer en el cuidado, alimentación, formación y educación de los hijos. Siendo el padre la figura de mando o autoritaria, pero en tanto icono o modelo, que tan solo con su presencia cumple su función, sin que sea necesario unas labores extras. Solo en algunos casos, se representa al padre como figura de juego.

\section{Estereotipos puestos en práctica}

A modo de conclusión, en este apartado se hará un acercamiento a la campaña de "Cafiaspirina" que circula entre finales de los veinte y principios de los treinta en las principales revistas del país y que articula los temas que hemos estado tratando en este artículo. La campaña representa a los personajes de una familia ideal y reproduce los roles de lo que debe ser el hombre y la mujer y sus funciones. Estas imágenes naturalizan los discursos de virilidad y hombría que se estaban construyendo. Se presenta una clara división entre lo masculino y lo femenino, con una campaña basada en un esquema de oposiciones.

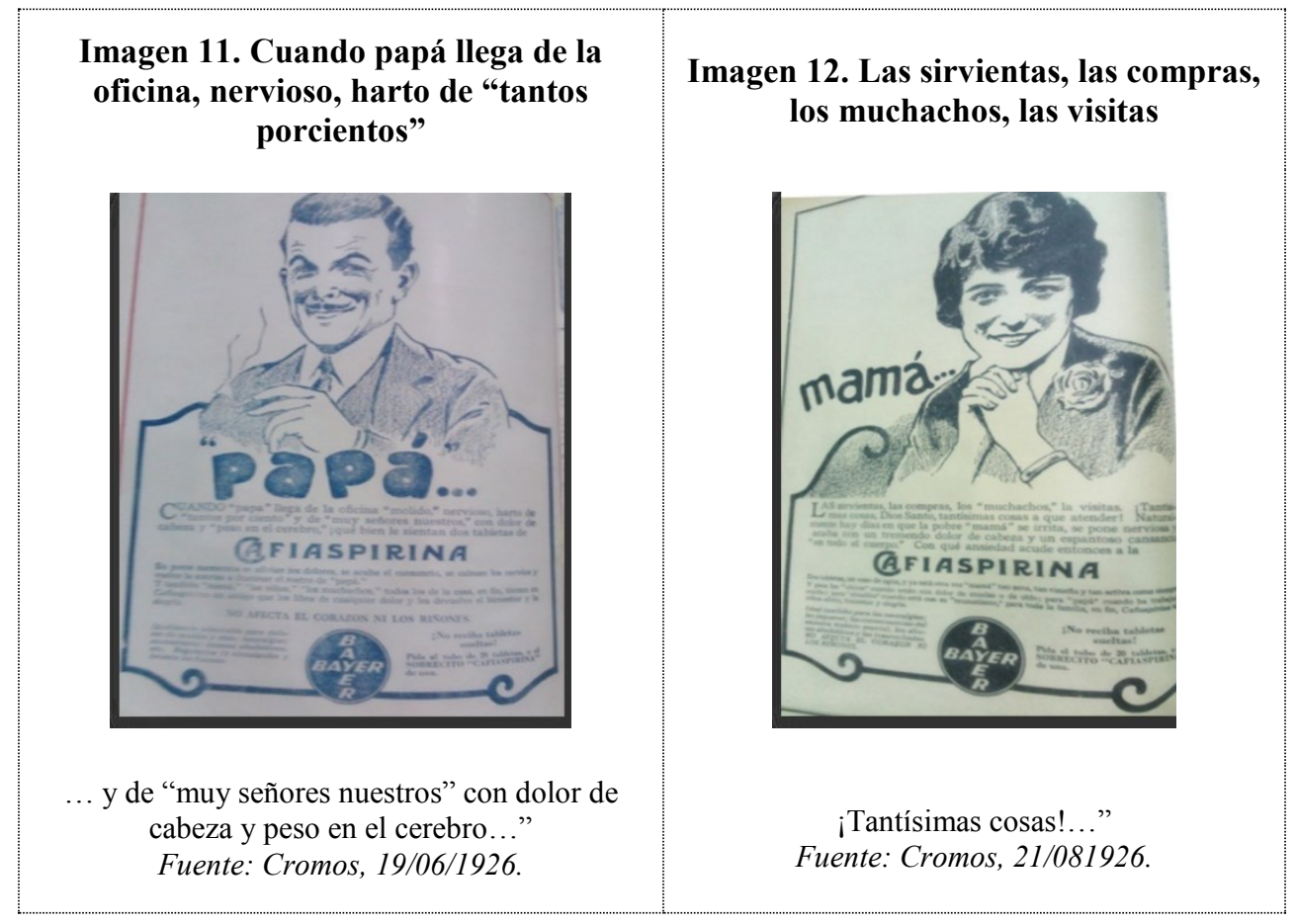

Los hombres deben tomar este medicamento por el cansancio que les genera el trabajo, o porque han tenido una noche de tragos, mientras que las mujeres lo deben tomar por sus dolencias innatas o su nerviosismo. Es el mismo producto para dolores ofertado, pero modela 
una figura y una escena diferente según el género y la edad. Como señala Faur "se observan que las nociones acerca de lo masculino se asocian con lo racional; fuerte; activo; productivo; valiente; responsable y conquistador (de territorios y de parejas ocasionales), mientras que lo femenino suele asociarse con lo emotivo; débil; pasivo; asustadizo; y dependiente." (Faur, 2004: 50). Estos estereotipos presentan un sistema de oposiciones binarias, en las que se identifica con mayor claridad cómo la identidad masculina es relacional y se construye por oposición con la feminidad. La mamá se cansa por cuidar a los hijos y la casa, mientras el papá por las arduas labores en su trabajo.

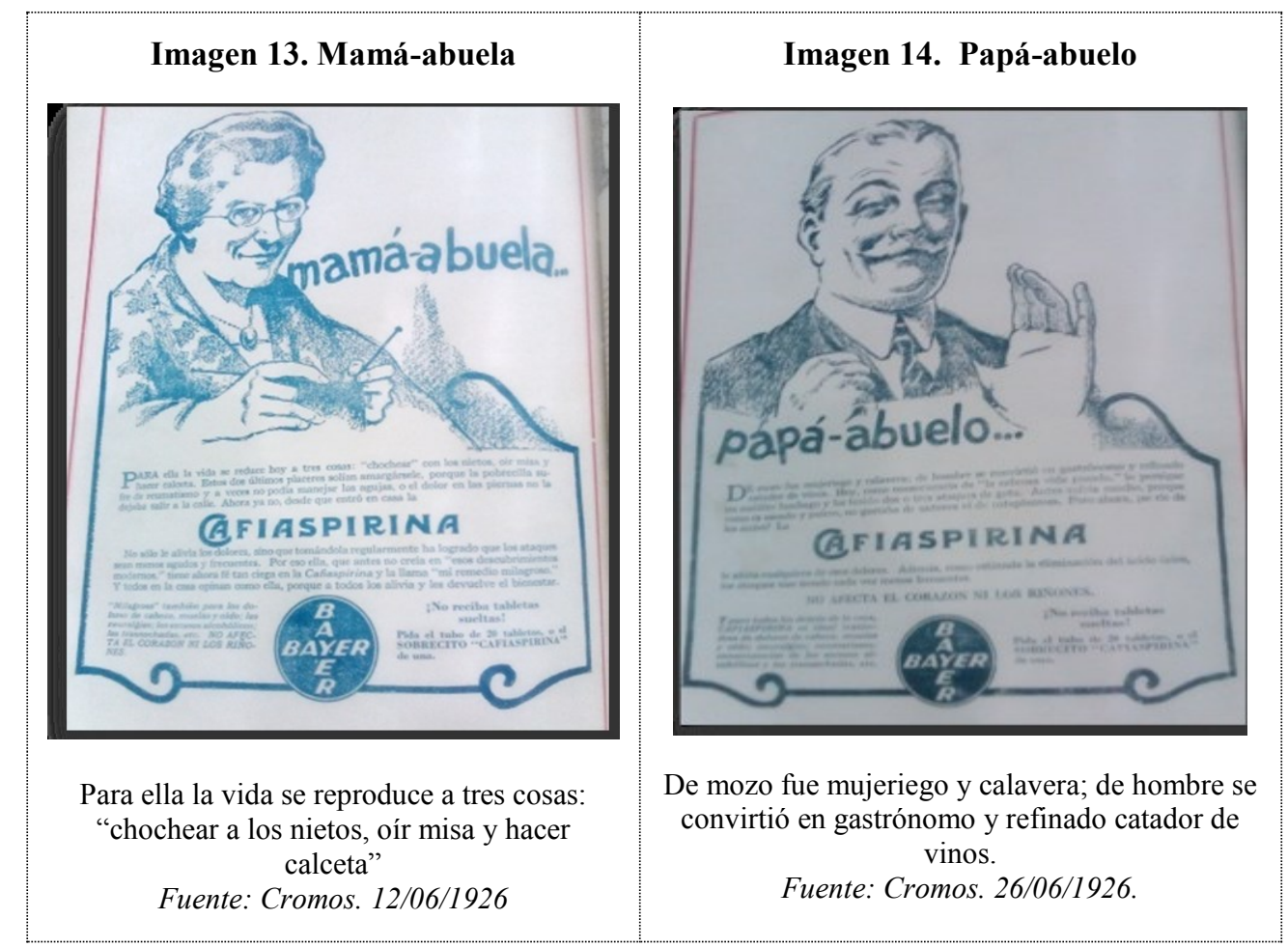

Desde la campaña de "Cafiaspirina", en la cual se puede advertir una distinción de los roles de género, se observa como el hombre se construye en lo que no es, lo no femenino, en relación a sus funciones sociales, tanto para entender su rol laboral, familiar y la propia historia de vida. La trayectoria de vida es valorada para el hombre pero desvalorada para la mujer como se ve en el caso de la campaña del abuelo, se habla de su vida pasada que pese a poder intuirse errada o apartada de la norma "De mozo fue mujeriego y calavera", se considera valiosa como experiencia y es lo que le propicia mayores conocimientos y capital social, sumando así a la configuración del modelo de lo masculino "de hombre se convirtió en gastrónomo y refinado catador de vinos"; mientras que la imagen de la abuela es presentada solo como la dedicada a la iglesia y a sus nietas, sin un pasado ni un presente, sin objetivos propios, sino dependiente de su esposo o sus nietos. "Para ella la vida se reproduce a tres cosas: "chochear a los nietos, oír misa 
y hacer calceta". En últimas la mujer no tiene una vida propia, sino como hemos visto su vida está dispuesta para el esposo y la familia. Estos modelos de la madre, el papá, el abuelo, va construyendo estereotipos.

En este artículo se ha querido examinar la representación de lo masculino y dar un panorama de las transformaciones que se advierten en las primeras décadas del siglo XX, para observar de qué manera se fueron estableciendo unos roles de género que aún permanecen. La figura del hombre como defensor de los débiles (niños o mujeres) sigue reproduciéndose como un valor social. La cultura física es un baluarte fundamental de esta sociedad, potencializado con los valores competitivos del deporte que se consideran afloran lo mejor del individuo. Estos aspectos representan y reproducen la función que se espera de cada individuo.

Como vimos a lo largo del texto, la imagen del hombre que se buscó consolidar en la primera mitad del siglo XX estaba dirigida a un cuerpo fuerte y sano capaz de defender la nación. La imagen de este hombre está enmarcada por lo sensorial, especialmente lo visual y lo sensual, con la difusión de dorsos de hombres desnudos que plantean un ideal de belleza. La virilidad y beligerancia se representaron como atributos propios del hombre guerrero. Esto en contraste de los atributos intelectuales que predominaron en el siglo XIX, con figuras como el dandy que se descollaban por la serenidad y la compostura. Los cafés y tertulias cedieron su lugar como espacio de sociabilidad masculina a los cuadriláteros de boxeo y coliseos deportivos.

Ahora bien, vale señalar en estas conclusiones que la construcción de ideal de masculinidad en representación del macho se extendió a todos los discursos que promovían el progreso y modernidad, siendo también un discurso político. Se puede apreciar como el proyecto del macho se expresó no solo en una alocución presidencial, sino que también transitó por las leyes de instrucción pública para la educación de los niños varones, hasta las imágenes publicitarias que muestran el cuerpo del hombre fuerte.

Si bien la noción de la masculinidad está sufriendo grandes transformaciones, podemos observar como los discursos de virilidad y hombría han estado siendo naturalizados por décadas. Son precisamente ante estos discursos arraigados del macho que se enfrentan los estudios de género y los debates que ponen en discusión las múltiples masculinidades que se pueden desarrollar de acuerdo a los contextos sociales, económicos, etc. Se espera que este artículo pueda aportar en los procesos de análisis e identificación los estereotipos dominantes, la forma en qué son construidos y su naturalización. Pues hoy en día, un siglo después de estas propagandas que hablan de la debilidad congénita de la mujer y la importancia de su cuidado personal, seguimos apreciando la proliferación de productos dirigidos para el cuerpo de la mujer; por ejemplo, para su "zona íntima", entre otros innumerables productos que dejan ver aún la idea que el cuerpo de la mujer es débil y propenso a la enfermedad. Igualmente, apreciamos un sinnúmero de propagandas que atribuyen al hombre cualidades de fuerza y competitividad que reducen el desarrollo individual a estereotipos de género. 


\section{BIBLIOGRAFÍA}

- Arango, Luz Gabriela; León, Magdalena y Viveros, Mara (1995) (eds): Género e identidad: ensayos sobre lo femenino y lo masculin ${ }^{\circ}$. Bogotá: Universidad Nacional de Colombia, Tercer mundo, Uniandes.

- Bonilla, Elssy (1985) (ed.): Mujer y familia en Colombia. Bogotá: Plaza \& Janés Editores.

- Bono Guardiola, María José (2006) (ed.): Los tratados para la mujer. Madame de Lambert. Alicante: Universidad de Alicante.

- Boscán Leal, Antonio Segundo (2006): "Propuestas Críticas para una Concepción no Tradicional de la Masculinidad”. En: Revista de Ciencias Humanas y Sociales, nº. 51, Año 22, Diciembre 2006, pp. 26-49, [en línea] Disponible en: http://www.scielo.org.ve/scielo.php?script=sci_arttext\&pid=S1012$15872006000300003 \& \operatorname{lng}=$ es\&tlng=es [9/05/2016].

- Bourdieu, Pierre (2000): La dominación masculina. Barcelona: Anagrama.

- Cabra, Nina y Roberto, Manuel (2014) (coord.): El cuerpo en Colombia. Estado del arte cuerpo y subjetividad. Bogotá: Universidad Central.

- Castro-Gómez, Santiago y Eduardo Restrepo (2008): (eds.): Genealogías de la colombianidad: Formaciones discursivas y tecnologías de gobierno en los siglos XIX y XX. Bogotá: Pontificia Universidad Javeriana.

- Connell, Robert W. (2003): Masculinidades. México: Universidad Nacional Autónoma de México.

- Coronado, María Suárez de (1925): "Discurso". En: Cromos, 06 de junio, vol. 20, nº 459.

- Cromos (1922): “Conferencia Femenina en Baltimore”, 10 de junio. vol. 9, nº 201.

- Cromos (1922): “Rafael Tanco, el Campeón Nacional”, 17 de julio. vol. 15, nº 312.

- Cromos (1923): "Feminismo y feministas", 04 de agosto, vol. 16, nº 365.

- Cromos (1924): “A todo hombre le deleita que su esposa sea fuerte, robusta y cariñosa..." 08 de octubre, vol. $15, \mathrm{n}^{\circ} .430$.

- Cromos (1929): "El médico sabe que la mujer moderna considera de mal gusto el estar enferma", 03 de agosto, vol. 28, $\mathrm{n}^{\mathrm{o}} .671$.

- Cromos (1933):“En las selvas amazónicas”, 24 de septiembre, vol. 22, nº 629.

- Cromos (1938): “Deportes”, 05 de marzo, vol. 47, no. 1114.

- Cromos (1939): "El Duce. Hombre fuerte y deportista", 07 de octubre, vol. 48, nº 1192.

- Cromos (1939): “La técnica de la popularidad a través de Benito Mussolini”, 07 de octubre, vol. $48, \mathrm{n}^{\circ} .1192$.

- Cromos (1943): “Pueblo sano. ¡Patria fuerte!”, 30 de enero, vol. 55, nº 1360.

- El Gráfico (1933): “El Libertador”, 21 de enero, nº 1119, p. 1.

- El País, Diario de la Mañana (1932): "Feliz año", 31 de diciembre, no 310, p. 1. 
- Faur, Eleonor (2004): Masculinidades y desarrollo social. Las relaciones de género desde las perspectivas de los hombres. Bogotá: UNICEF, Arango Editores.

- La frontera, (1932): "Soy soldado", 09 de noviembre, n. 3, p. 2.

- Mosse, George Lachmann (2001): La imagen del hombre: la creación de la masculinidad moderna. Madrid: Talasa.

- Pedraza, Zandra (1999): En cuerpo y alma: visiones del progreso y la felicidad. Bogotá: Universidad de los andes.

. (2011): "La estrategia higiénica: movimiento y regeneración". En: Revista Educación fisica y deporte, $\mathrm{n}^{\mathrm{o}}$. 30-1, pp. 445-456.

- Pérez, Pedro (1925): "Los Machos del Sr. Presidente. En: Cromos, 15 de agosto, vol. 20, nº. 469.

- Publicidad Kelpamalt (1936): “¡Débil, agotado, nerviosos, flaco!”. En: Cromos, 03 de octubre, vol. $48, \mathrm{n}^{\mathrm{o}} .1038$.

- Publicidad de Cafiaspirina (1926): "Mamá” Cromos, 26 de junio, vol. 22, no. 512.

- Publicidad de Cafiaspirina (1926): "Mamá-abuela" Cromos, 12 de junio, vol.21, no 510.

- Publicidad de Cafiaspirina (1926): "Papá” Cromos, 19 de junio, vol. 22, no. 511.

- Publicidad de Cafiaspirina (1926): "Papá-abuelo" Cromos, 17 de julio, vol. 22, no. 515.

- Publicidad Quaker Oats, (1924): “¡Hasta que caiga uno!” Cromos, 02 de agosto, vol. 18, nº. 418.

- Puluffo, Anna e Sánchez Prado, Ignacio M. (eds.) (2010): Entre hombres: masculinidades del siglo XIX en América Latina. Madrid: Iberoamericana; Frankfurt am Main; Vervuert.

- Ramos Santana, Alberto (1997) (coord.): La identidad masculina en los siglos XVIII y XIX: de la Ilustración al Romanticismo (1750-1850. VIII encuentro). Cádiz: Universidad de Cádiz.

- Sardà, Amparo Moreno y Rodríguez-Navas, Pedro Molina (2012): "La publicidad, fuente documental para explicar permanencias y cambios en las sociedades contemporáneas". En: Cuestiones de género: de la igualdad y la diferencia, $\mathrm{n}^{\circ}$ 7, pp. 177-195 [en línea] Disponible en: http://revpubli.unileon.es/ojs/index.php/cuestionesdegenero/article/view/909/799

- Suescun, María del Carmen (2007): "La Modernidad, el cuerpo y el orden político en Colombia". En: Zandra Pedraza (ed): Políticas y estéticas del cuerpo en América Latina. Bogotá: CESO.

- Viveros Vigoya, Mara (2002): De quebradores y cumplidores: sobre hombres, masculinidades y relaciones de género en Colombia. Bogotá: Universidad Nacional de Colombia, Fundación Ford, Profamilia. 